\title{
Article
}

\section{Boon or Bane: Using Antidepressants After Stroke}

Almeida, Osvaldo, Jones, Joshua, Hankey, Graeme J. and Hackett, Maree

Available at http://clok.uclan.ac.uk/36918/

Almeida, Osvaldo, Jones, Joshua, Hankey, Graeme J. and Hackett, Maree ORCID: 0000-0003-1211-9087 (2021) Boon or Bane: Using Antidepressants After Stroke. Maturitas . ISSN 0378-5122

It is advisable to refer to the publisher's version if you intend to cite from the work. http://dx.doi.org/10.1016/j.maturitas.2021.02.005

For more information about UCLan's research in this area go to

http://www.uclan.ac.uk/researchgroups/ and search for < name of research Group>.

For information about Research generally at UCLan please go to http://www.uclan.ac.uk/research/

All outputs in CLoK are protected by Intellectual Property Rights law, including Copyright law. Copyright, IPR and Moral Rights for the works on this site are retained by the individual authors and/or other copyright owners. Terms and conditions for use of this material are defined in the policies page.

\section{CLoK}

Central Lancashire online Knowledge www.clok.uclan.ac.uk

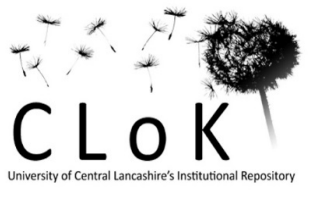




\section{Maturitas \\ Boon or Bane: Using Antidepressants After Stroke \\ --Manuscript Draft--}

\begin{tabular}{|l|l|}
\hline Manuscript Number: & \\
\hline Article Type: & Editorial \\
\hline Section/Category: & Aging, Care of older people: Editor in Chief - Leon Flicker \\
\hline Keywords: & depression; stroke; fractures; adverse events; fluoxetine; antidepressant \\
\hline Corresponding Author: & $\begin{array}{l}\text { Osvaldo P. Almeida } \\
\text { University of Western Australia (M577) } \\
\text { Perth, AUSTRALIA }\end{array}$ \\
\hline First Author: & Osvaldo P. Almeida \\
\hline Order of Authors: & Osvaldo P. Almeida \\
\hline & Joshua Jones \\
\hline & Graeme J. Hankey \\
\hline & Maree Hackett \\
\hline
\end{tabular}




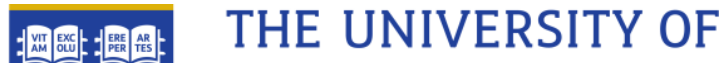 WESTERN AUSTRALIA}

Osvaldo P. Almeida MD, PhD, FRANZCP

Professor of Geriatric Psychiatry

Consultant, Royal Perth Hospital

\author{
WA Centre for Health \& Ageing \\ Medical School \\ University of Western Australia (M573) \\ 35 Stirling Highway | Crawley | WA 6009 \\ Australia \\ T +61-8-92242855 \\ $\mathrm{F} \quad+61-8-92248009$ \\ E osvaldo.almeida@uwa.edu.au \\ W www.wacha.org.au \\ CRICOS Provider Code: 00126G \\ Courier Address: \\ WA Centre for Health \& Ageing \\ Level 6 | Medical Research Foundation \\ Royal Perth Hospital \\ 50 Murray St (Rear) | Perth | WA 6000 | Australia
}

18 January 2021

Prof Leon Flicker

Editor, Maturitas

Dear Prof Flicker

$\underline{\text { Re: Boon or Bane: Using Antidepressants After Stroke }}$

Thank you for inviting us to contribute an editorial for Maturitas. Please find attached the relevant manuscript.

I would like to take the opportunity to thank you for allowing us to include one figure, eight references and three co-authors (four in total) in this editorial.

I look forward to hearing from you.

With kind regards

Osvaldo P. Almeida (on behalf of the authors) 


\section{Boon or Bane: Using Antidepressants After Stroke}

The results of the fluoxetine in motor recovery of patients with acute ischaemic stroke (FLAME) trial $(\mathrm{n}=118)$ showed that stroke survivors treated with fluoxetine had better motor function than their counterparts treated with placebo for 3 months [1]. Three large randomised placebo-controlled trials were subsequently designed to confirm these preliminary findings: the fluoxetine or control under supervision (FOCUS) trial $(n=3127)$, the assessment of fluoxetine in stroke recovery (AFFINITY) trial $(n=1280)$, and the efficacy of fluoxetine randomised controlled trial in stroke (EFFECTS) $(n=1500)$ [2-4]. The three trials found that daily treatment with $20 \mathrm{mg}$ of fluoxetine for 6 months after acute stroke does not improve functional outcomes, but increases the risk of bone fractures [2-4]. These findings raised significant concerns regarding the safe use of fluoxetine in this population, but need to be balanced against potential benefits, such as the prevention of depression.

The FLAME trial used the Montgomery-Åsberg Depression Rating Scale (MADRS) to assess depressive symptoms at study entry and after 3 months. The scores of participants treated with placebo increased significantly more than for those treated with fluoxetine. In FOCUS and AFFINITY, depression was defined as a new clinical diagnosis recorded during trial followup that required treatment with an antidepressant $[2,4]$, whereas in EFFECTS the need for antidepressant use was not required [3]. The fluoxetine and placebo groups were well balanced for all relevant measures at the time of randomisation in the three trials. FOCUS and EFFECTS, but not AFFINITY, found that treatment with fluoxetine decreased the odds of depression among study participants. Such findings offer some reassurance that treatment with fluoxetine may prevent post-stroke depression (most participants were not depressed at randomisation), but fail to address the risk-benefit issue associated with the use of fluoxetine. For this reason, we pooled the unadjusted published data for these three trials to estimate the risk ratio of 
depression and fractures, and respective 95\% confidence limits (95\%CL). We used a random effects restricted maximum likelihood (REML) model to summarise the depression and fracture data from the three trials, and calculated the absolute risk reduction (ARR) for depression and the absolute risk increase (ARI) for fractures associated with fluoxetine use. The number needed to treat (NNT) is the reciprocal of the ARR and the number needed to harm $(\mathrm{NNH})$ is the reciprocal of the ARI. The risk benefit ratio (RBR) was calculated as the ARI/ARR. RBR $>1$ indicates that treatment is associated with harm, and results $<1$ with benefit.

The figure shows the unadjusted distribution of depression and fractures in the FOCUS, AFFINITY and EFFECTS trials: 6 months of treatment with fluoxetine was associated with a decreased pooled risk of depression and an increased risk of fractures. The ARR of depression associated with fluoxetine use was $3.37 \%$, whereas the ARI of fractures was $1.76 \%$. The NNT to prevent one case of depression was 30 and the NNH to cause a fracture was 56 . The RBR was 0.52 .

\section{FIGURE}

The mechanism linking fluoxetine to fractures in this population is most likely associated with its negative effect on bone density [5], higher risk of falls [2,4], or it could be due to increased activity among stroke survivors without depression. This increased risk should be an area of concern for the practicing clinician, despite fractures being a relatively uncommon clinical complication in this population. Indeed, the 6-month probability of new depression following a stroke was 10 times greater than new fractures. With 30 people with stroke requiring treatment with fluoxetine for six months for one person to avoid depression, the use of 
fluoxetine for the prevention of depression should not be dismissed. Systematic review evidence indicates that antidepressants may be similarly useful in preventing depression after a stroke [6], and longitudinal data from other sources suggest that antidepressants may have no lingering effect on the risk of fractures in later life, as other competing risk factors for fractures, such as history of past fractures and frailty, are likely to override small detrimental effects associated with the use of antidepressants [7].

We would suggest that the potential increase in the risk of fractures associated with the use of fluoxetine is overshadowed by its ability to prevent depression after stroke, although these are but two among numerous clinical outcomes that clinicians must consider when making decisions about how best to manage these patients. Instead of refraining from using fluoxetine (or another antidepressant [8]), it may be more helpful to consider alternative strategies to reduce the risk of fractures in this population, such as addressing factors associated with falls (e.g., sedatives and polypharmacy) and the early introduction of measures to manage osteopenia and osteoporosis. Weighing up risks and benefits associated with interventions, as well as managing competing risk factors associated with undesirable health outcomes, continues to be core business for competent clinicians.

\author{
Osvaldo P. Almeida, MD, FRANZCP \\ Joshua Jones, BPharm \\ Graeme J. Hankey, MD, FRACP \\ Maree Hackett, $\mathrm{PhD}$
}


Author affiliations: Medical School, University of Western Australia, Australia (OPA, JJ, GJH); The George Institute for Global Health, Faculty of Medicine, University of New South Wales, Australia; The University of Central Lancashire, Faculty of Health and Wellbeing, University of Central Lancashire, Preston, UK (MH)

\section{Author contributions:}

Concept and design: Almeida, Hackett and Hankey.

Acquisition, analysis or interpretation of data: Almeida, Jones, Hackett and Hankey.

Drafting of the manuscript: Almeida.

Critical revision of the manuscript for important intellectual content: Almeida, Jones, Hackett and Hankey.

Conflict of interest disclosures: none reported.

Funding source: none.

Correspondence: Osvaldo P. Almeida, WA Centre for Health \& Ageing (M577), University of Western Australia, Perth, WA 6009, Australia. E: osvaldo.almeida@uwa.edu.au. 


\section{References}

[1] F. Chollet, J. Tardy, J.F. Albucher, C. Thalamas, E. Berard, C. Lamy, et al. Fluoxetine for motor recovery after acute ischaemic stroke (FLAME): a randomised placebo-controlled trial. Lancet Neurol 10 (2011) 123-130.

[2] AFFINITY Trial. Collaboration. Safety and efficacy of fluoxetine on functional outcome after acute stroke (AFFINITY): a randomised, double-blind, placebo-controlled trial. Lancet Neurol 19 (2020) 651-660.

[3] EFFECTS Trial Collaboration. Safety and efficacy of fluoxetine on functional recovery after acute stroke (EFFECTS): a randomised, double-blind, placebo-controlled trial. Lancet Neurol 19 (2020) 661-669.

[4] FOCUS trial Collaboration. Effects of fluoxetine on functional outcomes after acute stroke (FOCUS): a pragmatic, double-blind, randomised, controlled trial. Lancet 393 (2019) 265274.

[5] M.J. Ortuno, S.T. Robinson, P. Subramanyam, R. Paone, Y.Y. Huang, X.E. Guo, et al. Serotonin-reuptake inhibitors act centrally to cause bone loss in mice by counteracting a local anti-resorptive effect. Nat Med 22 (2016) 1170-1179.

[6] S. Allida, K.L. Cox, C.F. Hsieh, A. House, M.L. Hackett. Pharmacological, psychological and non-invasive brain stimulation interventions for preventing depression after stroke. Cochrane Database Syst Rev 5 (2020) CD003689.

[7] O.P. Almeida, G.J. Hankey, J. Golledge, B.B. Yeap, L. Flicker. Depression and the risk of fractures in later life: the Health In Men Cohort Study. Maturitas 145 (2021) 6-11.

[8] K.L. Kraglund, J.K. Mortensen, A.G. Damsbo, B. Modrau, S.A. Simonsen, H.K. Iversen, et al. Neuroregeneration and Vascular Protection by Citalopram in Acute Ischemic Stroke (TALOS). Stroke 49 (2018) 2568-2576. 


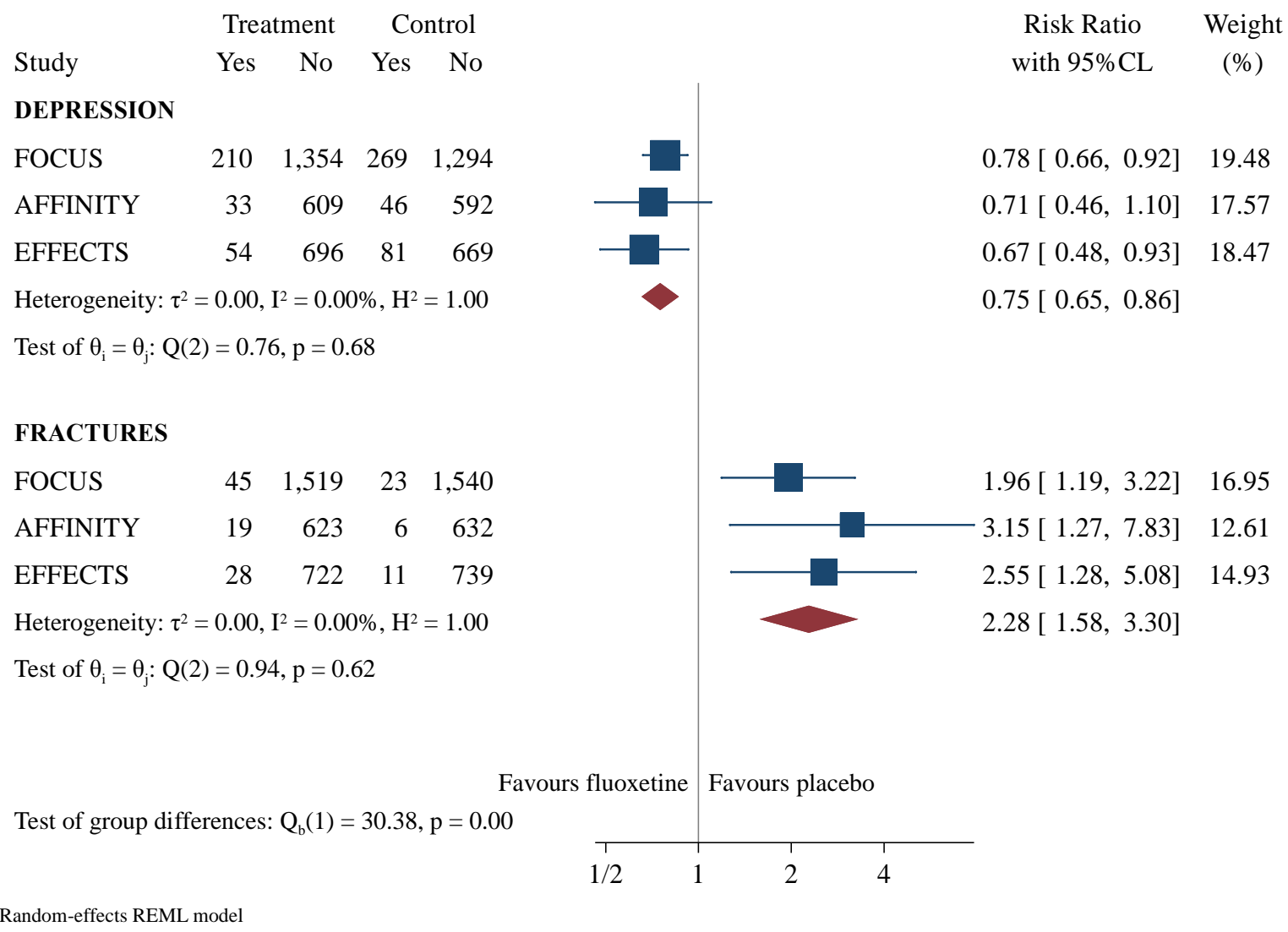

Figure 1. Forest plot showing the unadjusted effects of fluoxetine use for 6 months on the risk of post-stroke depression (new depression since randomisation) and fractures. 
Conflict of Interest

\section{$\underline{\text { Declaration of interests }}$}

The authors declare they have no conflicts of interest. 